\title{
NOVEL QUATERNARY AMMONIUM COMPOUNDS BASED ON PYRIDOXINE AND FATTY ACIDS: DESIGN, SYNTHESIS AND ANTIBACTERIAL ACTIVITY
}

\section{S. Sapozhnikov, N. Shtyrlin, A. Strelnik, N. Egorova, M. Belova, E. Trizna, M. Agafonova, E. Bulatova, A. Kayumov, Y. Shtyrlin}

Scientific and Educational Center of Pharmaceutics, Kazan (Volga region) Federal University, 420008, Russia, Kazan, Kremlyovskaya street, 18.

DOI: 10.19163/MedChemRussia2021-2021-35

E-mail:SVSapozhnikov@kpfu.ru

Quaternary ammonium compounds (QACs) are the most important class of antiseptics exhibiting high antibacterial, antifungal and antiprotozoal activity. A number of QACs (miramistin, benzalkonium chloride, dequalinium chloride) have been widely used for clinical practice.

In previous work [1] we synthesized QACs which include cleavable moieties (amide, ester) and a six-membered acetals and ketals of pyridoxine bound via linker moiety with a fragment of fatty carboxylic acid (structure I). The lead compounds showed high antibacterial activity in vitro $(\mathrm{MIC}=0,5-4 \mu \mathrm{g} / \mathrm{ml})$ and were non-toxic in vivo $(\mathrm{LD} 50>2000 \mathrm{mg} / \mathrm{kg})$ at oral and cutaneous administration on mice. In this work we have expanded the library of QACs containing fragments of fatty acids. The new compounds (structure II and III) are bis-analogs of structure I. In addition, compounds containing quaternized nitrogen in the pyridine ring and a fatty acid fragment were obtained (structure IV). The study of the antibacterial activity of 3 series of compounds showed that lead compounds have high antibacterial activity (MIC $=1-4 \mu \mathrm{g} / \mathrm{ml}$ ) comparable with reference antiseptics miramistin, benzalkonium chloride and chlorohexidine.

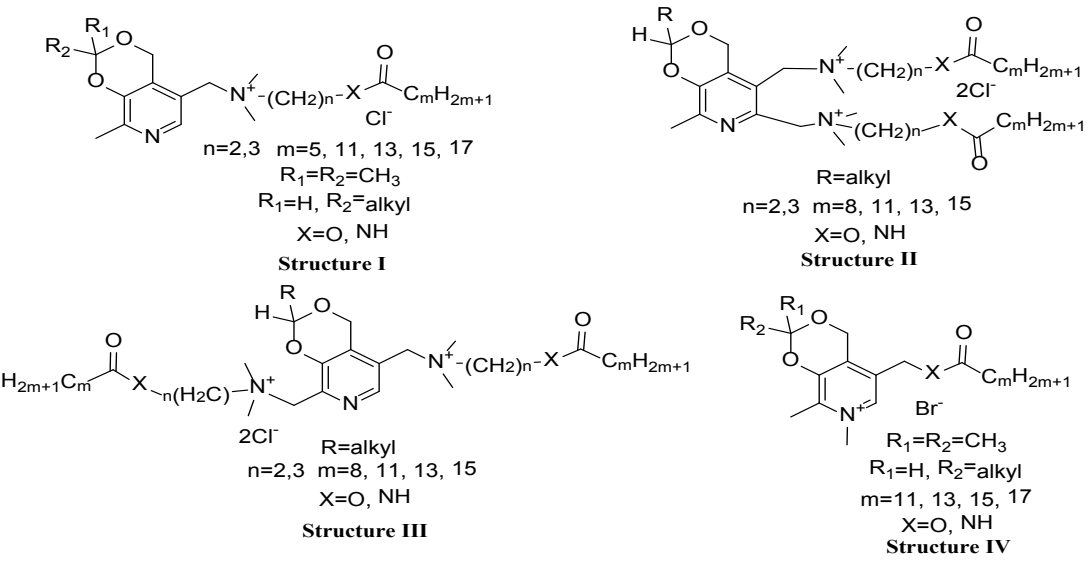

This work was supported by subsidy allocated to Kazan Federal University for the state assignment in the sphere of scientific activities (project number 0671-2020-0053).

\section{Reference}

[1] S.V. Sapozhnikov, A.E. Sabirova, N.V. Shtyrlin, A.Y. Druk, M.N. Agafonova, M.N. Chirkova, R.R. Kazakova, D.Y. Grishaev, T.V. Nikishova, E.S. Krylova, E.V. Nikitina, A.R. Kayumov, Y.G. Shtyrlin, Eur.J. Med. Chem., 2021, 211, 113100. 